\title{
Developing a Structured OJT Program: The Case of a Small Manufacturing Company in a Rural Region
}

\author{
Raymond A. Dixon \\ University of Idaho
}

This study explored the process followed by a small manufacturing company in a rural area to implement a planned training program to develop the technical skills of its engineering/production workers as the company expands its operation. A case study design was used. Data was collected over an eight-month period by the examination of documents, direct observation, and interview. Findings indicate the process followed were consistent with elements of the Talent Development Architecture. The growth of the company presents learning opportunities for both the owner and his management team. The job analysis provided inputs to implement a planned training program and to develop documents to support talent development. To maintain a pipeline of skilled entry-level workers, partnership needs to be built with the high school CTE program.

Keywords: structured OJT, job analysis, CTE, small and medium-sized enterprises, talent development

The barriers and challenges to training and development, a traditional form of talent development, in small and medium-sized enterprises (SMEs) are varied and may include factors related to the size of the enterprise, turnover, type of business, senior management views and commitment to training, industrial relations climate, and the policies of the government (Padachi $\&$ Bhiwajee, 2016). Some owners and managers of SMEs tend to ignore the central value of developing their human assets because the long-term investment that is often required is seen as an interference with the day-to-day activities of their business, which often necessitates quick and easy solutions and concentration on short term profitability (Beaver \& Hutchings, 2005; Panagiotakopoulos, 2011). According to Padachi and Bhiwajee, (2016), the cost that is associated with the training of workers also acts as a barrier to it being carried out in a formal manner in SMEs (Padachi \& Bhiwajee, 2016). SMEs face financial pressure to keep their business afloat and competitive, and investment in training is often viewed as a luxury that involves unproductive labor- something that SMEs owner-managers cannot afford. Additionally, SMEs often do not have the relevant human resource management specialists to devote to training activities (Beaver \& Hutchings 2005; Jameson, 2000; Kotey \& Slade, 2005).

Particularly in rural regions of the USA, where it is difficult to find and attract skilled workers, reluctance to invest in training may be motivated by the risk of losing skilled talent through poaching by competitors, or trained workers establishing their own business and becoming competitors to their former employers (Saru, 2007). Studies have also shown that 
when SMEs carry out on-the-job training (OJT), they are usually informal, ad-hoc, and illconceived - devoid of training needs analysis and a systemic structured approach to the training (Jameson, 2000; Johnston \& Loader, 2003; Panagiotakopoulos, 2011).

This study examined how a small manufacturing company that is on the verge of expanding and which operates in a rural region, develops its capacity to provide planned or structured OJT (S-OJT) to advance the technical competency of its manufacturing staff and to create a pipeline of skilled workers in order to address challenges to recruit and retain manufacturing workers. The following questions guided this study:

1. How were the tasks for S-OJT systematically identified?

2. How were mentors/coaches prepared to carry out S-OJT?

3. What is the strategy to partner with CTE in the local high school?

4. To what extent does the process to implement planned training reflects the talent development architecture?

\section{Review of Literature}

In nonmetropolitan regions, talent development enacted through OJT by some SMEs is an important human resource development (HRD) strategy because the acquisitions of skilled workers from the external market is often challenging (Lepak \& Snell, 1999). Garavan et al. (2012) define talent development as:

The planning, selection and implementation of development strategies for the entire talent pool to ensure that the organization has both the current and future supply of talent to meet strategic objectives, and that development activities are aligned with organizational talent management processes. (p. 6)

Often talent development constitutes the full scope of HRD activities within SMEs in which HRD is often defined by terms such as training \& development, learning, competency development, formal job-related training, and management training and development. In SMEs, development strategies are often less strategic and more informal and idiosyncratic, demonstrated through practices that are more embedded within the context of normal, daily operations, and routines (Barrett, 2015; Beaver \& Hutchings 2005; Coetzer et al., 2012; Nolan \& Garavan, 2016; Vickerstaff, \& Parker, 1995). The general focus is to resolve pressing workrelated problems concerned with performance deficits, managing skills shortages, and creating a mobile and flexible workforce - rather than addressing long-term people development strategy (Kotey \& Folker, 2007; Morgan et al., 2008; Walker et al., 2007). This informal approach, or socalled deficit model of HRD, in SMEs is often accredited to the lack of managerial resources and expertise to identify skill deficiencies, and so is looked upon as inferior, unorganized or even non-existent (Garavan et al., 2012). So, while most studies extol the virtues of formal training and development (e.g., Bryan, 2006; Rauch et al., 2005), informal training and development is often seen as substandard or mediocre. Such perception may be influenced by the predominant positivist empirical designs used to examine constructs associated with development in large organizations, without much consideration of the goodness-of-fit of informality to SMEs, in view of the different contexts in which they operate. Johnson and Devins (2008) warned of the dangers of an uncritical reading of statistical evidence, maintaining that "existing survey-based measures of training activities do not take sufficient account of the informal flexible nature of 
much workforce development" (p. 2) that take place in SMEs. Kuchinke (2003) also acknowledged that mainstream HRD models fail to account for the context-dependent nature of HRD and variation in strategies and processes.

Informality supposedly indicates that SMEs lack strategy in respect to the development of their talent. When viewed, however, through the lenses of strategic choice, informality may be appropriate in view of the constraints under which small organizations operate and may be more effective in enhancing business performance. Other researchers argued that the vulnerability and external uncertainties facing SMEs, make short-term, reactive, informal approach to HRD an apposite response, and such a response is strategic in addressing the company's competitive advantage and survival (Patton \& Marlow, 2002). As manufacturing companies in rural areas grow, they are cognizant their need for a skilled workforce will increase, so strategies will need to be put in place to ensure they have a steady supply of skilled workers. This is crucial for them to maintain and improve the quality of their products and services and to remain competitive. Under these circumstances they are likely to shift to more planned programs to develop the skills of their workers.

Structured On-The-Job Training. The development of the technical and professional skills of workers can take various forms and one of such is on-the-job training (OJT). Traditional OJT is often unstructured. This means, according to Furst-Bowe and Gates (1998), they tend to not have written documentation; lack proper monitoring by supervisors; lack the use a formal process to select the trainer; has no development of the skills of the trainer; suffers from competing goals between training and production; and exhibits inconsistency in structure of the training process, materials, and methods. In contrast, structured S-OJT is properly planned and is systematic. Jacobs (2003) described it as the planned, intentional process of using a more experienced worker to train a less experienced worker in the development of specific competencies for the job, at or near the work setting.

S-OJT consists of several critical components, these include laying out the general skills for the job before learning specific skills, preparing mentors, codifying training procedures, establishing schedule for the training, and evaluating the training process while reinforcing skills (Ahadi \& Jacobs, 2017; Molnar \& Watts, 2002). Jacobs (2003) further identified 5 steps when carrying out S-OJT. They include 1) prepare the trainee, 2) present the training, 3) require a response, 4) provide feedback, and 5) evaluate performance.

S-OJT has proven to reduce the time spent learning a task in various work settings (Jacobs et al., 1992). It also increases the job satisfaction level of workers who participated in it and the opportunity of workers to make progress in their relationship with their managers (Ahadi \& Jacobs, 2017). Trainers who participated in S-OJT experience increase in their organizational commitment, occupational commitment, and efficacy (Cho, 2009). Workers who were involved in S-OJT get the chance to implement, evaluate, and troubleshoot each step of their duties and tasks, and this contributed to a positive increase in their behavior on the job (Ahadi \& Jacobs, 2017). When compared to OJT, the implementation of S-OJT in manufacturing also reduces production errors.

The implementation and delivery of S-OJT can be done by a supervisor, job coach, a coworker, or a facilitator. It is successful when there is strong support from management, accessibility of employees who needs to participate in the training program, documented tasks analysis, and available trainers, coaches, or mentors (Jacobs, 2003; Sisson, 2001). 
Attracting skilled workers: The role of CTE. Manufacturing provides a higher share of jobs and earnings in rural (nonmetropolitan) areas than in urban (metropolitan) areas, however, manufacturing companies in rural areas often struggle to recruit and retain skilled workers (USDA, 2017). As manufacturers contemplate the need to grow and remain competitive, they are compelled to recognize the strategic importance of attracting, recruiting, and retaining workers who possess the technical and social competencies integral to the core functions of their organization. This is often in the context of a limited available pool of skilled workers. According to Bozarth and Strifler (2019):

Not only are rural areas less densely populated, their populations are getting older, on average, due to both outmigration of younger people, and, in some cases, older adults retiring to rural areas. As of mid-2018, those 65 and older make up almost a quarter of the population in nonmetro areas, and prime working-age adults (defined as those who are 25 to 54 years old) comprise less than half (43 percent) of the population. (p. 3 )

Speaking to the need to attract and retain millennials to rural areas, Njemanze (2016) articulated several strategies for successful recruitment and retention. Specific recommendations include actively targeting prospects most likely to accept job offers and fit in culturally; providing formal professional development support; expending equal efforts to attract and retain a candidate's partner and family; and offering non-traditional benefits such as flexible work, educational benefits, home loan/mortgage assistance.

CTE programs offered in schools and colleges relevant to industries in their region is critical for the supplying of a steady source of skilled workers. However, developing a pipeline of skilled workers for manufacturing companies in rural areas is sometimes hampered by the lack of CTE programs in K-12 schools. Many of these schools in the Pacific Northwest, dismantled their CTE programs during the recent great recession (Stricklin et al., 2015). For those schools that do have CTE programs, the curriculum may not be rigorous enough to provide the job and occupational specific skills for students to function proficiently in entry-level positions. Stronger regional collaboration; employer involvement; support from the state government, college and university systems, and industries; can increase and strengthen CTE programs in rural schools (Lerman, 2010). When the forgoing happens, students are better informed about CTE programs and the well-paying job opportunities that exists, and they are more likely to choose career pathways in manufacturing (Bozarth \& Strifler, 2019). Ultimately, this will develop a steady supply of skilled workers for the local manufacturing industry and its economy. SMEs in rural regions, therefore, should not only embrace strategies to develop skills from within the company but also partner with CTE programs in regional high schools.

The Framework: Talent Development Architecture. Lepak and Snell (1999) suggested a differentiated approach to talent development based on contributions employees make to the business, an approach that is opposite to the one size fits all orientation. Consistent with this orientation, Gandz (2006) suggested the notion of a talent development pipeline architecture that consists of a clear statement of development needs, developmental pathways, and an effective HR system to support identification, assessment, and development of talent (see also Garavan et al., 2009). 
Articulation of talent needs. Talent development needs are articulated for large organizations mostly through competency maps, which are frameworks that are typically standardized across units of the organization and are used to identify individual and business unit developmental needs (Isrealite, 2010). Systematic formal talent review processes are also used by many organizations to assess future development potentials, particularly for high potential workers (Garavan et al., 2012). Talent development in SMEs, however, would likely be driven by the owner-manager perceived views of existing skills deficiency that need to be addressed to meet product and customer requirements (Mukokho \& Beatrice, 2016).

Creating developmental pathways. Developmental pathways constitute the experience, exposure, and challenges workers must be engaged in and work through to emerge as the talent for the future (Grandz, 2006). Structured experiences can enhance the understanding of complex organizational cultural and business issues. It enables respect for differences, improve organizational relationship, and enhance networking skills (Carpenter et al., 2000). Exposure refers to opportunities to work in different contexts and situations and are achieved through job rotation, secondments, projects, and international assignments. They help to develop technical expertise, judgment, strategic thinking, and business acumen (Evans et al., 2011; Yost \& Mannion-Plunkett, 2010). Developmental challenges include incidents such as business turnaround, start-up, downsizing, expansion, or closure. These incidences allow employees to deal with stressful changes, learn from mistakes and failures, and increase their awareness of hidden constraints (Garavan et al., 2012, p.11). There is evidence in the literature that SMEs' owners and employees strongly believe that informal, on-the-job experiential workplace methods are very important to job competency development, because of their context-specific nature and the important socialization they offer (Higgins et al., 2013; Nolan \& Garavan, 2016; Paloniemi, 2006; Perry et al., 2010).

System to support identification, assessment, and development of talent. System processes to support talent development include human resource planning, effective selection of talent, performance management, career management, and succession planning (Garavan et al., 2012). Because human resource systems are less formalized in SMEs and usually comes under the portfolio of the owner-manager, the execution of development strategies are less developed and systematic and may be contingent in nature (McDonnel \& Collings, 2011).

Programs to enable talent development. The type of programs that organizations utilize to develop talent falls into four categories; formal programs, relationship-based developmental experiences, job-based development experiences, and informal/non-formal development activities (Conger, 2010; Garavan et al., 2009; Byham et al., 2002). The results of SMEs response to formal developmental activities are mixed, with some studies reporting a positive association between the use of formal talent development approaches and improved worker and staff motivation (Huang, 2001; Pajo et al., 2010). Other studies indicate employees in SMEs respond more positively to informal approaches (Harris, 2009; Kock \& Ellstrom, 2011).

\section{Methodology}

A single case study design with a critical sample was used. Scholz and Tietje (2002) defined case study as "an empirical inquiry that investigates a contemporary problem within its real-life context" (p. 9). Yin (2003) stipulated that case study research is an appropriate strategy 
when the researcher is interested in contemporary events and cannot control or manipulate behavioral events. A critical sample represents an exceptional case from which the researcher can study the phenomenon. It falls within the purposeful sampling techniques where the researcher intentionally selects individuals and sites because they will help the researcher to learn or better understand the phenomenon (Patton, 1992).

The Case. Pacific Cabinets Inc. is a manufacturing company operating in the Inland Northwest in a county with a population of 16,156 and a population percentage growth rate less than the national average. Established over 38 years ago, the company was founded on the premise of employing people from the local community. Pacific Cabinets Inc. teams up with architects and contractors to provide clients with premium furnishings in healthcare, education, and lab facilities. Their products include casework, countertops, millwork, and specialty products. Services include estimation consultation, design and engineering, project management, and manufacturing. With an increasing demand for its products, the company was faced with the decision to either relocate its manufacturing facilities to another region where skilled workers are easily available or enlarge its facilities and continue to serve the community where the company was born but is often difficult to recruit and retain skilled workers (Personal Communication, 2016). The decision was made to increase its manufacturing space by constructing a new 20,000square-foot manufacturing facility. The new facilities would automate the manufacturing of corian countertops, plastic laminate tops, medical headwalls, and highly customized items such as nurse stations. The expanded facility would increase production by approximately 30 percent, and the number of new hires by about fifty.

Procedure. After being invited by the owner-manager of Pacific Cabinets Inc. as a part of the team for initial consultation about the plans of the company, the researcher sought permission to observe the process to its implementation. Although this was a busy time of expansion and transition, the owner-manager was agreeable to having someone external to the company examine the process.

Data Collection and Analysis. Data was collected over six months by the examination of documents and direct observations. Documents examined included position guides for engineering job functions, satisfaction surveys from the job analysis and train the trainer workshops, and notes from meetings with the management team and consultants from economic and workforce development. The two interventions, job analysis and train the trainer workshops, were observed for their full duration. An interview was conducted with the operations manager about six months after the S-OJT was implemented.

A time series analysis was used (Yin, 2018). The research questions reflected the sequence in which activities occurred in the company. Data was analyzed for research question 1 by coding the notes taken doing the meetings of the owner and his management team with the workforce development experts and the regional economic development representatives for themes and subthemes. Notes from the job analysis workshop was also coded for themes and subthemes.

Notes taken from observation of S-OJT train-the-trainer workshop, and the satisfaction surveys done by the participants were coded for themes and subthemes to answer research question 2. Transcription from interview with the operations manager was coded for themes and 
subthemes related to research questions 3 and 4 . To ensure trustworthiness the findings were compared with the competency profile chart developed by the company, the curriculum of the SOJT train-the-trainer workshop, and the operations manager was allowed to examine the findings related to each of the research questions.

\section{Findings}

Research Question 1. How were the tasks for S-OJT systematically identified?

Workforce development experts briefed the management team about approaches to develop the skills of workers, taking into consideration external contexts such as training institutions and funding opportunities. Among the options discussed were having a private vendor provide customized training; partnering with the nearest two-year college to provide online modules, while the company provides hands-on experience; and OJT that follows a more planned format. Information was received from the department of labor local agency regarding financial assistance that was available to SMEs for the training of workers. The owner-manager decided the company would invest in identifying and codifying the competencies of a key job function in the engineering/production department as the first step to implementing a S-OJT program in the company.

The job analysis carried out was a worker-oriented groupware process known as DACUM (Halasz, \& Reid, 2003). Workers considered to be experts by the management team were selected to participate in a job analysis workshop. Over a period of two days and under the guidance of a trained facilitator they delineate the job, Project Engineer/CNC Programmer, into its duties and tasks. They also identified the general knowledge and skills, attitudes, and tools required for the job. Table 1 illustrates the duties and tasks identified by expert workers. Some general knowledge and skills identified included algebra and trigonometry, problem-solving, time management, written and verbal communication, and knowledge of manufacturing processes. Some attitudes important for this job were, attention to detail, willingness to ask questions, and interpersonal relationship.

\section{Table 1}

Duties and Tasks of Project Engineer/CNC Programmer

\begin{aligned} & \hline Duties and Tasks \\ & \hline A. Perform Project Research \\ & A-1. Participate in kick-off meetings E. Generate Material Requisition \\ & A-2. Identify material E-1. Quantify material \\ & A-3. Review specifications E-2. Submit requisition \\ & A-4. Review drawings E-3. Track material status \\ & A-5. Review budgets E-4. Monitor material usage \\ & A-6. Review schedule \\ & A-7. Identify custom production \\ & \\ & B. Create Project Set-ups G. Produce Production/ Custom Work Order \\ & B-1. Develop specification sheet F-1. Assess workflow efficiency \\ & B-2. Input project information F-2. Create manufacturing details \\ & B-3. Develop specification groups F-3. Generate MV report \\ & B-4. Validate material files F-4. Generate Ardis report \\ & \hline\end{aligned}


B-5. Create custom cabinet(s)
B-6. Break down phasing

C. Produce Submittal Drawings

C-1. Layout CAD drawings

C-2. Input library product

C-3. Design custom products

C-4. Generate detail manual

C-5. Annotate/Dimension Drawings

C-6. Publish paper space

C-7. Update PM-correction

D. Update Project Modifications

D-1. Incorporate redline changes

D-2. Incorporate field verification

D-3. Incorporate R.F.I. changes

D-4. Resubmit changed documents
F-5. Compile work order packet

F-6. Review work order

F-7. Release work order

F-8. Generate needs list

F-9. Communicate with relevant work personnel

H. Generate CNC Programming

G-1. Review manufacturing details

G-2. Verify cut list

G-3. Retrieve Auto-CAD drawings

G-4. Add machine layers to CAD drawing

G-5. Apply layers to geometry

G-6. Cross-check programming/ Auto-CAD drawing with manufacturing details

G-7. Send to post processor

J. Perform Administrative Function

H-1. Generate As-builts

H-2. Complete O\&M manual

H-3. Report project summary

H-4. Track monthly goal

H-5. Participate in weekly schedule meetings

H-6. Assist in company/

departmental development

H-7. Conform to A.W.S. requirements

H-8. Participate in personal development

Research Question 2: How were mentors/coaches prepared to carry out S-OJT? The owner and his management team decided it would be strategic to implement a S-OJT program. A consultant was employed, and workers who met the following five criteria; availability, desire to teach, likeability, job knowledge, and the ability to cause learning; were selected by the management team to participate in the train-the-trainer workshop. These workers were trained to be mentor/coaches. Nine workers participated in the train-the-trainer workshop. Content covered include:

- Conducting task analysis

- Producing job aids

- Developing lesson plans

- Instructional strategies

- Conducting performance assessment

Some tasks identified by the job analysis were broken down into steps or procedures by the participants during the workshop. The group continued their task analysis of the remaining competencies in the weeks following the workshop. They also developed lesson plans and performance assessments for all competencies. Consistent with Jacobs' (2003)

recommendations, mentors were trained to prepare the trainee, deliver the training, observe the trainee performing the task, and provide feedback.

The workers who participated in both the job analysis workshop and S-OJT training felt it equipped them to address the development of skills in their organization in a more systematic manner, a strategic need of the organization in view of the expected growth. They commented: 
The opportunity to get all tenured people in a room and agree on one process... Seeing how everyone looks at it was both interesting and informative ...eye opening, I did not realize there was a process that focuses on worker competencies in lieu of a training regimen.

One of the most valuable things I learned from the course was planning effectively by analysis on what somebody with no knowledge of the subject matter needs to understand in order to learn.

The course presents a new perspective on how to breakdown a process and organize it in order to teach it.

Very good course, very valuable. I was happy to find out that my training methods for the most part was on track-just needed mor refining.

What I appreciate the most was breaking down the tasks into logical, chronological steps...

Research Question 3: What is the strategy to partner with CTE in the local high school? The operations manager indicated that to "address access to future talent, they also need to work more closely with the nearby high school." This was more pragmatic in view of the distance of the technical college from the company. Tasks from the competency profile that aligns with the state CTE standards will be identified and infused in the computer aided drawing and designing (CADD) curriculum of the high school. The high school will be given access to equipment and software to enhance students' CADD skills, and workers from the company will be allowed to provide mentorship for students and expertise resource to the CTE teacher. The partnership with the school will also include internship and apprenticeship opportunities for students. The management team are also mindful that CTE is offered as an elective and many students are not aware of career choices in CTE, and even fewer students show interest in manufacturing careers. This is an area that need continued attention by the company as they engage in long-term partnership with the school. The operations manager stated:

We have not seen a lot of interest for drafting or engineering positions with the kids in high school, despite inquiring about paid internships, but we also know it takes a long time to train for these positions and generally won't get a lot out of that training period other than a potential future hire... We hope to continue to establish something with high school students to ensure future interest and workforce for our company and have recently been looking into information on some apprenticeship programs that may aid this effort.

Research Questions 4: To what extent does the process to implement planned training reflects the talent development architecture? The planned expansion of the company's production facilities and the decision of the owner to keep the company's operation in the region spurred the management team to think about strategies to ensure it had a pipeline of skilled workers. The process of exploring these strategies was developmental for the 
management team, as it broadens their understanding of the role regional agencies and institutions can play in helping companies as they expand.

\section{Figure 1}

Talent Development Architecture of the SME

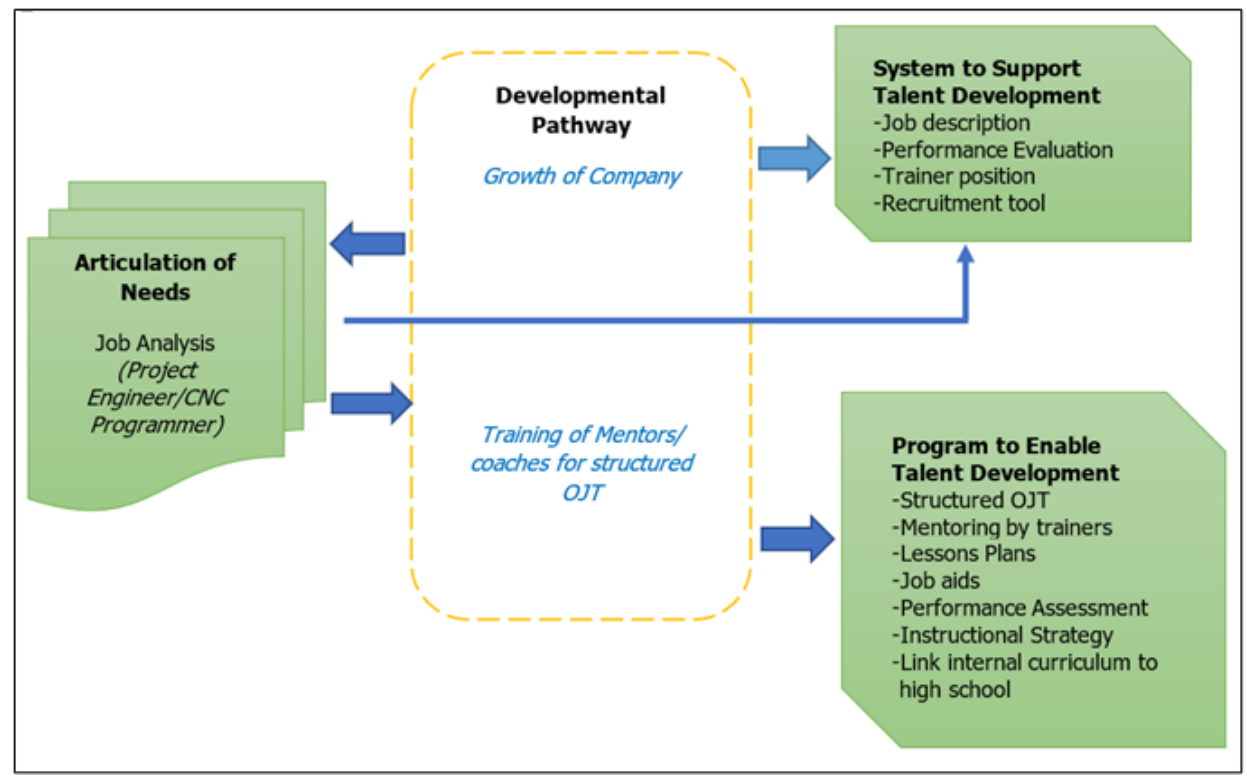

Through consultation with the regional economic association and workforce development experts from the university, the management team learnt about state and federal assistance for companies to implement OJT and apprenticeship programs. They learnt about various strategies to train skilled workers and the advantages and disadvantages of each. The availability of funding from the state to help to implement OJT was instrumental in influencing the ownermanager to make the decision to implement a planned training program. The process of articulating the needs of the company led to an analysis of the Project Engineer/CNC Programmer job and a subsequent competency profile chart.

As Figure 1 illustrates, the competency profile was used by the company to aid in the development of job descriptions and performance evaluation forms, which will help in their expanding human resource function. The company also created a new position, Engineering Trainer, which will contribute to the system to support talent development.

We have created a new trainer in our company for engineering .... I used to have to come up with a unique training program for each hire and spend quite a bit of time lining up individuals to train each specific specialty as well as maintain an overall handle on 
the progress. Now the program is doing this for us and we have trusted other trainers to utilize the program to handle all of our new hires for this position. We get even results and can modify it as we go.

The operations manager indicated that the existence of the S-OJT program also serves as a useful recruitment tool, as potential employees are attracted to the company when they learn they can receive training on the job.

... It is also a valuable recruitment tool as many people are excited to hear during an interview that we do have a training program in place.

Because of the existence of S-OJT, they were able to effectively fill new positions since the company's expansion.

All in all, the DACUM and structured-OJT programs have been a success. We are fortunate to have been able to fill all our positions and recently are finding we have more interest in our positions than we have a need for. We have increased confidence that we can adequately train them and that our current workforce needs are being met so our decision to stay and expand here has been successful.

The training of mentors/coaches for the S-OJT program was also another developmental opportunity, specifically for worker in engineering/production. They were trained to conduct tasks analysis, produce job aids, develop lessons plans, demonstrate procedure, and provide effective feedback and assessment.

\section{Discussion}

Hill and Stewart (2000) concluded HRD practices, such as training and development, in SMEs reflect some form of the vast array of strategies or approaches reported in the academic and practitioner literature on the subject. In this case study, the owner-manager recognized the need to build the company's capacity to provide structured training as it prepares for expansion. This was an important strategic positioning - to create a pipeline of skilled workers in order to address challenges to recruit and retain workers in manufacturing. To achieve this goal, they sought assistance from the regional economic develop association and workforce development experts from a research university. The actions by the owner-manager are consistent with what Finegold and McCarthy (2010) identified as crucial collaborative efforts that are needed between community agencies, training institutions, and companies for the development of high skilled workers and to allow for "ongoing skills development and progression from entry-level jobs" ( $p$. 200). The decision by the owner-manager to implement the two types of interventions was contingent on three factors. First, the decision to remain in the region because of a strong social connection to community and a commitment to continue contributing to the economy of the region, that is, to remain as the main employer in manufacturing. Second, the availability of financial assistance from the state to fund the implementation of OJT in companies. And third, availability of workforce development experts in the region to provide training to implement a S- 
OJT program. The absence of these factors might have resulted in a different decision by the owner-manager.

The willingness of the selected workers to participate in the workshops for the job analysis and S-OJT shows they supported this strategic decision by management to systematize training and development. According to Arnold et al. (2016), "satisfactory job analyses are prerequisites for many decisions and activities that have a crucial influence on the lives of employees within the organization" (p.121), including training and career development schemes. Scott and Leach (2001) articulated the need to use expert or master workers as trainers in planned OJT, but also stipulated they must not be selected purely for their content knowledge but based on intelligent decisions according to job competence, training ability and ability to communicate effectively. The S-OJT train the trainer workshop used a list of criteria for the selection of mentors/coaches, and with the help of the management team worker were identified who met these criteria. Some of the expert workers who previously participated in the job analysis workshop were also selected to be trained as mentors and coaches for S-OJT. An important finding from this case study is the value felt by workers who participated in the job analysis and the S-OJT train the trainer workshops. They seemed to appreciate that their expertise and value to the company was being recognized by the owner and his management team, as the company grows into a larger organization. To demonstrate this recognition, the names of the expert panel who participated in the job analysis workshop were placed on the competency profile chart, and the profile chart became a permanent record of the human resource department. There were also early indications that the workers who were trained as mentors/coaches for S-OJT had a positive perception of their job and the company (Ahadi \& Jacobs, 2017).

Figure 2 illustrates how the choices made and processes followed by the management team related to the talent development architecture. The growth of the company presented developmental challenges and opportunities for the management team as they learned about strategies to develop the skill of their workforce, and assistance that are available through various agencies and institutions. It provided learning for workers who had to adjust to the expansion of the company through participation in two interventions, the job analysis and the train the trainer workshop for the S-OJT. The outcomes of the process to structure its OJT all related to elements of the talent development architecture. This indicates the architecture does not only depict what happens in large companies where human resource development activities are structured, but small expanding companies that seek to structure their training activities will reflect elements of the architecture. The company's decision to establish a trainer position in the engineering/production department demonstrates the owner and his management team acknowledgement that as the company grows, training and development processes will need to become more formalized.

Recruitment and partnership with CTE. The competency profile from the job analysis provided information to aid in the creation of detailed job/position description and performance evaluation forms, documents that will aid in the support of talent development. Perhaps surprisingly, is the unexpected impact that awareness of the S-OJT program helped in the recruitment of new employees to the company. However, this is consistence with the Strengthening Workforce Development in Rural Areas Brief, which recommends that recruiting and retaining manufacturing workers "should go beyond wages, and include skills development, 
career advancement opportunities, tuition assistance, and flexible scheduling" (Bozarth, \& Strifler, 2019, p. 6). Pacific Cabinets Inc. will be strengthening their partnership with the local high school. They appreciate that partnership with schools to nurture and grow interest in CTE and manufacturing through mentorship for students, plant tours, sharing of equipment and resources, and internship/apprenticeship programs can produce a steady stream of potential workers who are qualified for entry-level positions in manufacturing.

\section{Conclusion}

This case study provides insight into how a small manufacturing company operating in a rural region, implements a S-OJT program as it makes plans for expansion, and the perceived engagement that is necessary with the CTE program in the local high school in order to address the supply of skilled workers to their company. It examines how the process followed, reflects the talent development architecture that usually defines how larger companies address talent development in their organization. While this case study cannot be generalized to other companies, it provides a deeper understanding and adds to the literature on how HRD activities may evolve as a small manufacturing organization grows into a larger entity. Further research needs to compare multiply cases of small companies in different regions to identify the commonality and differences as HRD activities evolve from being unstructured to more structured.

\section{References}

Arnold, J., Randall, R., Patterson, F., Silvester, J., Robertson, I., Harris, D., Cooper, C., Burnes, B., \& Axtell, C. (2016). Work psychology: Understanding human behavior in the workplace. (6 ed.) Pearson Education Limited.

Ahadi, S., \& Jacobs, R. L. (2017). A Review of the literature on structured on-the-job training and directions for future research. Human Resource Development Review, 16(4) 323349. https://doi.org/10.1177/1534484317725945

Barrett, R. (2015). Small firm training: Just meeting the day-to-day needs of the business. Employee Relations, 37(5), 547 - 567. https://doi.org/10.1108/ER-05-2014-0048

Beaver, G., \& Hutchings, K. (2005). Training and developing an age diverse workforce in SMEs: The need for a strategic approach. Education and Training, 47(8/9), 592-604. https://doi.org/10.1108/00400910510633134

Bozarth, A., \& Strifler, W. M. (2019). Strengthening workforce development in rural areas: 2019 Federal Reserve System. https://www.investinwork.org/-/media/Files/reports/strengtheningworkforce-development-rural-areas.pdf

Bryan, J. (2006). Training and performance in small firms. International Small Business Journal, 24(6), 635-660. https://doi.org/10.1177/0266242606069270

Byham, W. C., Smith, A. B., \& Paese, M. J. (2002), Grow your own leaders: How to identify, develop, and retain leadership talent. Financial Times Prentice Hall.

Carpenter, M. A., Sanders, W. G., \& Gregersen, H. B. (2000). International assignment 
Journal of Research in Technical Careers

experience at the top can make a bottom-line difference. Human Resource Management, 39(2-3), 277-85. https://doi-org.uidaho.idm.oclc.org/10.1002/1099-

050X(200022/23)39:2/3\%3C277::AID-HRM15\%3E3.0.CO;2-0

Coetzer, A., Redmond, J., \& Sharafizad, J. (2012). Decision making regarding access to training and development in medium-sized enterprises. European Journal of Training and Development, 36, 426-447. https://doi.org/10.1108/03090591211220348

Cho, D. (2009). Impact of structured on-the-job training (S-OJT) on a trainer's organizational commitment. Asia Pacific Education Review, 10, 445-453. https://doi.org/10.1007/s12564-009-9037-9

Conger, J.A. (2010). Developing leadership talent: Delivering on the promise of structured programmes. In Silzer, R. and Dowell, B. E. (Eds.), Strategy-driven talent management: A leadership imperative (pp. 281-312). Jossey-Bass.

Evans, P. A., Smale, A., Bjorkman, I., \& Pucik, V. (2011). Leadership development in multinational firms. In Storey, J. (Ed.), Leadership in organizations: Current issues and key trends. Routledge.

Finegold, D., \& McCarthy, J. (2010). Creating a sector skill strategy: Developing high-skill Ecosystems. In D. Finegold (Eds.), Transforming the U.S. workforce development system: Lessons from research and practice (pp. 181 - 204). Labor and Employment Relations Association.

Furst-Bowe, J., \& Gates, D. (1998, March). Assessing the effectiveness of OJT: A case study approach. In R. J. Torraco (Ed.), Proceedings of the Academy of Human Resource Development (pp. 367-371). Academy of Human Resource Development.

Garavan, T. N., Carbery, R., \& Rock, A. (2012). Mapping talent development: Definition, scope and architecture. European Journal of Training and Development, 36(1), 5-24. https://doi.org/10.1108/03090591211192601

Garavan, T. N., Hogan, C., \& Cahir-O'Donnell, A. (2009). Developing managers and leaders: Perspectives, debates and practices in Ireland. Gill \& Macmillan.

Gandz, J. (2006, January/February). Talent development: The architect of talent pipeline that that works. Ivey Business Journal Online, 70(3), pp. 1-4. https:/iveybusinessjournal.com/publication/talent-development-the-architecture-of-atalent-pipeline-that-works/

Halasz, I. M., \& Reid, T. (2003). Overview of DACUM job analysis process (Report No. 4). http://static. nicic.gov/Library/010699.pdf

Harris, R.J. (2009). Improving tacit knowledge transfer within SMEs through e-collaboration. Journal of European Industrial Training, 33(3), 215-231. https://doi.org/10.1108/03090590910950587

Higgins, D., Mirza, M., \& Drozynska, A. (2013). Power, politics and learning: A social enactment of the SME owner/manager. Journal of Small Business and Enterprise Development, 20, 470-483. https://doi.org/10.1108/JSBED-04-2013-0050

Hill, R., \& Stewart, J. (2000). Human resource development in small organizations. Journal of European Industrial Training, 24 (2, 3, 4), 105-117. https://doi.org/10.1108/03090590010321070

Huang, T.C. (2001). The relation of training practices and organizational performance in small and medium size enterprises. Education + Training, 43(8/9), 437-444. https://doi.org/10.1108/00400910110411620

Isrealite, L. (2010). Thinking about talent. In Israelite, L. (Ed.), Talent management strategies for success from six leading companies (pp. 1-14), ASTD Press.

Jacobs, R. L. (2003). Structured on-the-job training: Unleashing employee expertise in the workplace. Berrett-Koehler.

Jacobs, R. L., Jones, M. J., \& Neil, S. (1992). A case study in forecasting the financial benefits 
of unstructured and structured on-the-job training. Human Resource Development Quarterly, 3, 133-139. https://doi.org/10.1002/hrdq.3920030205

Jameson, M. (2000). Recruitment and training in small firms. Journal of European Industrial Training, 24(1), 43-49. https://doi.org/10.1108/03090590010308255

Johnson, S., \& Devins, D. (2008). Training and workforce development in SMEs: Myth and reality. SSDA Catalyst Issue 7. UK Commission for Employment and Skills

Johnston, K., \& Loader, K. (2003). Encouraging SME participation in training: Identifying practical approaches. Journal of European Industrial Training, 27(6), 273-280. https://doi.org/10.1108/03090590310479901

Kock, H., \& Ellström, P. (2011). Formal and integrated strategies for competence development in SMEs. Journal of European Industrial Training, 35(1), 71-88. http://dx.doi.org/10.1108/03090591111095745

Kotey, B., \& Slade, P. (2005). Formal human resource practices in small growing firms. Journal of Small Business Management, 43(1), 107-127. https://doi.org/10.1111/j.1540-627X.2004.00123.x

Kotey, B., \& Folker , C. (2007). Employee training in SMEs: Effect of size and firm-typefamily and nonfamily. Journal of Small Business Management, 45(2), 214-238. https://doi.org/10.1111/j.1540-627X.2007.00210.x

Kuchinke, K. P. (2003). Contingent HRD: Toward a theory of variation and differentiation in formal human resource development. Human Resource Development Review, 2(3), 294-309. https://doi.org/10.1177/1534484303256885

Lepak, D. P., \& Snell, S. A. (1999). The human resource architecture: Toward a theory of human capital allocation and development. The Academy of Management Review, 24(1), 31-48. https://doi.org/10.2307/259035

Lerman, R. I. (2010). Employee-led training: extensive and intensive approaches. In D. Finegold (Eds.), Transforming the U.S. workforce development system: Lessons from research and practice. Champaign, IL: Labor and Employment Relations Association, University of Illinois at Urbana-Champaign (pp. 153 - 180).

McDonnell, A., \& Collings, D. G. (2011). The identification and evaluation of talent in MNEs, In Scullion, H. and Collings, D. G. (Eds.), Global Talent Management. Routledge.

Molnar, J., \& Watts, B. (2002). Structured on the job training: Effectively training employees with employees [A research report of the center for entrepreneurial studies and development, INC]. West Virginia University. http://www.cesd.wvu.edu

Morgan , A., Raidén , A., \& Naylor, G. (2008). Unlocking the potential to influence government skills policy: A case study of the UK construction industry. International Journal of Training and Development, 12(4), 238-252. https://dx.doi.org/10.1111/j.1468-2419.2008.00309.x

Mukokho, A. A., \& Beatrice, O. (2016). Strategic choice, organizational learning, top management team processes and firm performance: A critical literature review. EPRA International Journal of Economic and Business Review, 4(2), 24-31.

Nolan, C.T., \& Garavan, T. N. (2016). Human resource development in SMEs: A systematic review of the literature. International Journal of Management Reviews, 18, 85-107. https://doi.org/10.1111/ijmr.12062

Njemanze, I. (2016). How can firms located in rural areas better position themselves to attract and retain millennial talent? http://digitalcommons.ilr.cornell.edu/student/111/

Padachi, k., \& Bhiwajee, S. L. (2016). Barriers to employee training in small and medium sized Enterprises: Insights and evidences from Mauritius. European Journal of Training and Development 40(4), 232-247. https://doi.org/10.1108/EJTD-02-2014-0018

Pajo, K., Coetzer, A., \& Guenole, N. (2010). Formal development opportunities and withdrawal 
behaviours by employees in small and medium-sized enterprises. Journal of Small Business

Management, 48, 281-301. https://doi.org/10.1111/j.1540-627X.2010.00295.x

Panagiotakopoulos, A. (2011). Barriers to employee training and learning in small and medium sized enterprises (SMEs). Development \& Learning in organisations, 25(3), 15-18. https://doi.org/10.1108/14777281111125354

Paloniemi, S. (2006). Experience, competence and workplace learning. Journal of Workplace Learning, 18, 439-50. https://doi.org/10.1108/13665620610693006

Patton, M. Q. (1992). Qualitative evaluation and research methods ( ${ }^{\text {rd }}$ ed.). Sage Publications, Inc.

Patton, D., \& Marlow, S. (2002). The determinants of management training within smaller firms in the UK. What role does strategy play? Journal of Small Business and Enterprise Development, 9, 260-270. https://doi.org/10.1108/14626000210438580

Perry, J., Badger, B., Lean, J., \& Leybourne, S. (2010). Taking over the reins: the needs of individuals who purchase small established enterprises. International Journal of Entrepreneurship and Innovation, 11, 57-67. http://people.bu.edu/sleyb/IJEI\%20\%20Taking\%20over\%20the \%20reins.pdf

Rauch, A., Frese, M., \& Utsch, A. (2005). Effects of human capital and long-term human resources development and utilization on employment growth of small-scale businesses: A causal analysis. Entrepreneurship Theory and Practice, 29(6), 681-698. https://doi.org/10.1111/j.1540-6520.2005.00103.x

Saru, E. (2007). Organisational learning and HRD: How appropriate are they for small firms? Journal of European Industrial Training, 31(1), 36-51. https://doi.org/10.1108/03090590710721727

Scholz, R. W., \& Tietje, O. (2002). Embedded case study methods: Integrating quantitative and qualitative knowledge. Sage Publications, Inc.

Scott, S. D., \& Leach, J. A. (2001). Using Expert Employees to Train on the Job. Advances in Developing Human Resources, 3(4), 425-434. https://doi.org/10.1177/15234220122238481

Sisson, G. (2001). Hands-on training: A simple and effective method for on the job training $\left(1^{\text {st }}\right.$ ed.). Berret-Koehler Publishers, Inc.

Stricklin, L., Dixon, R. A., \& Holyoke, L. (2015). Collaborative partnership to address workforce education in a rural region: A case study. Online Journal for Workforce Education and Development, 8(1), 1-23.

Walker, E., Redmond, J., Webster, B., \& Le Clus , M. (2007). Small business owners: Too busy to train? Journal of Small Business and Enterprise Development, 14(2), 294-306. http://dx.doi.org/10.1108/14626000710746718

USDA (August 2017). Rural Manufacturing at a Glance. Economic Research Service, Economic Information Bulletin 177, https://www.ers.usda.gov/

Vickerstaff, S., \& Parker, K. T. (1995). Helping small firms: The contribution of TECs and LECs. International Small Business Journal, 13(4), 56-72. https://doi.org/10.1177\%2F0266242695134003

Yin, R. K. (2003). Case study research: Design and methods (3ed). Sage Publications, Inc.

Yin, R. K. (2018). Case study research and application: Design and methods (6ed). Sage Publications, Inc.

Yost, P. R., \& Mannion-Plunkett, M. (2010). Developing leadership talent through experiences. In Silzer, R. and Dowell, B. E. (Eds.), Strategy-Driven Talent Management, $\left(1^{\text {st }}\right.$ ed., pp 313-49). Jossey-Bass. 